\title{
Extraction and optimization of chitosan from razor clam (Ensis arcuatus) shells by using response surface methodology (RSM)
}

\author{
*Zamri, A.I., Latiff, N.F., Abdullah, Q.H. and Ahmad, F. \\ Faculty of Fisheries and Food Science,University Malaysia Terengganu, 21030 Kuala Nerus, Terengganu, \\ Malaysia
}

\begin{abstract}
Article history:
Received: 3 September 2019

Received in revised form: 10

December 2019

Accepted: 14 December 2019

Available Online: 30

December 2019
\end{abstract}

Keywords:

Optimization,

Extraction,

Ensis arcuatus,

Response surface

methodology,

Chitosan

DOI:

https://doi.org/10.26656/fr.2017.4(3).308

\section{Introduction}

Razor clam is classified in genus Ensis or known as 'Siput buluh' among the locals in Malaysia. This species is abundant in the intertidal sandy beaches and mudflats along the western coast of Malaysia (Na, 2008; Rabuyan and Bakar, 2016), mostly in Selangor and Johor as well as at the eastern coast, Kuching and Samarahan and collected by the locals as the economic sources. As razor clam had been widely commercialized in Malaysia, the waste particularly the shells of this species may cause environmental pollution. By utilizing the shells for chitosan extraction, the source of pollution may be reduced significantly. Previous study proved that chitosan extracted from razor clam can act as a natural coagulant and able to remove the turbidity in water in a water treatment process (Adenan, 2009). In this study, chitosan was extracted from razor clam at the optimized condition to be used as an edible film in the food industry.
In nature, chitin is usually extracted from the exoskeleton of crustaceans, squid pens, fungi, and mollusc. Chitosan is a universal natural polysaccharide, mainly consisting copolymers of glucosamine and $\mathrm{N}$ acetylglucosamine, and can be acquired by the partial deacetylation process of chitin which included enzymatic means or alkali deacetylation method. Optimization by response surface methodology has been employed to carry out optimization studies as it can assist in determining the interactive impact of process variables and in plotting a mathematical model that precisely describes the whole process (Mourabet et al., 2017). The objective of this study was to statistically optimize the independent process parameters such as deacetylation time (hrs) and deacetylation temperature $\left({ }^{\circ} \mathrm{C}\right)$ by randomized D-optimal design in response surface methodology and to evaluate the chemical properties of chitosan extracted from razor clam shells. 


\section{Materials and methods}

\subsection{Materials}

Fresh razor clam, Ensis arcuatus was obtained from Pulau Ketam, Selangor, Malaysia. Razor clam was collected fresh from the seashore and was kept at $4^{\circ} \mathrm{C}$ prior to use. Analytical grade Hydrochloric acid $(\mathrm{HCl})$ $(20 \%)$ and sodium hydroxide $(\mathrm{NaOH})(2 \%, 10 \%$, and $50 \%)$ were used in chemical extraction. The chemical used for this project was acquired from Merck Sdn. Bhd, Malaysia.

\subsection{Extraction of chitosan}

\subsubsection{Preparation of the razor clam shells}

The razor clam flesh was separated from the shells. The shell was washed before dried using the oven (Memmert UF 110 , Germany) at $70^{\circ} \mathrm{C}$ for $4 \mathrm{hrs}$ or until the moisture content (\%) reached between $8-10 \%$. Chitosan was extracted according to Zainal et al. (2014) with slight modifications. Dried shell was crushed by using a blender (Waring 8010S-HGBTWTS3, USA) and then passed through $60-120 \mu \mathrm{m}$ mesh sieves to obtain finer and consistent particles powder.

\subsubsection{Demineralization}

The powder was soaked and agitated in $20 \% \mathrm{HCl}$ for $16.5 \mathrm{hrs}$ at the ratio of $1: 5$ of shell powder to the acid solution at room temperature. This step was repeated twice (Majekodunmi, 2016). The powder was then treated with $2 \% \mathrm{NaOH}$ until neutral $\mathrm{pH}$ was obtained.

\subsubsection{Deproteination}

The powder obtained from the demineralisation process was then immersed in $10 \% \mathrm{NaOH}$ solution at the ratio of $1: 5$ of sample to the solution at $70^{\circ} \mathrm{C}$ in water bath shaker (Memmert SV 1422, Germany) for $2 \mathrm{hrs}$. The mixture was cooled at room temperature $\left(\sim 26^{\circ} \mathrm{C}\right)$ and rinsed using distilled water until neutral $\mathrm{pH}$ was obtained.

\subsubsection{Deacetylation}

The powder was soaked in $50 \% \mathrm{NaOH}$ solution at the ratio of 1:5 of sample to the solution and then was treated with $\mathrm{NaOH}$ at $\left(50,60,70,80\right.$ and $\left.90^{\circ} \mathrm{C}\right)$ for $(2,4$, 68 , and $10 \mathrm{hrs}$ ) in water bath shaker, then filtered in purpose to obtain the solid matter which is chitosan powder.

\subsubsection{Purification of chitosan}

Chitosan powder was treated with $0.01 \mathrm{M} \mathrm{HCl}$ solution at the ratio of 1:5 of sample to the solution. The mixture was centrifuged at $1370 \mathrm{x} g$ for 15 mins. The collected, supernatant, was dried in the vacuum oven (Protech Model-ADP 21, Japan) at $60^{\circ} \mathrm{C}$ for $4 \mathrm{hrs}$ or until the moisture content reached between $8-10 \%$.

\subsection{Characterization of extracted chitosan powder}

\subsubsection{Percentage yield}

Yield (\%) of chitosan was calculated as the total weight of chitosan powder to the total razor clam shells used.

$$
\text { Yield }(\%)=\frac{\text { Chitosan powder }(\mathrm{g})}{\text { Razor clam shells }(\mathrm{g})} \times 100
$$

\subsubsection{Degree of deacetylation}

Degree of deacetylation was determined by direct titration according to Sarbon et al. (2015). The calculation of degree of deacetylation was made by using the following equation:

Degree of deacetylation $(\%)=\frac{161.16 *(\mathrm{~V} 2-\mathrm{V} 1) \mathrm{N}}{\mathrm{W} 1}$

Where $\mathrm{V} 1$ = final volume of $\mathrm{NaOH}$ solution; $\mathrm{V} 2$ = initial volume of $\mathrm{NaOH}$ solution; $\mathrm{N}=$ strength of the $\mathrm{NaOH}$ solution $(0.1 \mathrm{M})$; and $\mathrm{W} 1=$ mass of sample after correction for moisture. Mass of chitosan monomer is 161.16.

\subsubsection{Molecular weight}

Molecular weight (kDA) was determined according to Kurniasih and Dewi (2018). Molecular weight (kDA) was calculated using Mark Houwink-Sakurada equation:

$$
[\eta]=\mathrm{K}\left(\mathrm{M}_{\mathrm{v}}\right)^{\alpha}
$$

Where $[\eta]=$ intrinsic viscosity; $\mathrm{M}_{\mathrm{v}}=$ Molecular weight; and $\mathrm{K}$ and $\alpha$ are $1.81 \times 10^{-3}$ and 0.93 respectively.

\subsubsection{Ash content}

Ash content was determined according to AOAC (1990) method.

\subsection{Optimization of extracted chitosan}

Optimization of chitosan extraction was done using Design Expert Software (Version 11.1.2.0), Stat Ease, USA. Response surface methodology (RSM) using Doptimal design of 2-factors-5-levels was employed to develop predictive models for different responses. The experimental design produced 16 runs (conditions) in which was carried out to obtain the optimum condition of the factors. In this study, factors of time $\left(X_{1}\right)$ and temperature of deacetylation $\left(\mathrm{X}_{2}\right)$ were chosen as the independent variables, with five levels at $(2,4,6,8,10 \mathrm{hrs})$ and $\left(50,60,70,80\right.$ and $\left.90^{\circ} \mathrm{C}\right)$. Yield (\%), degree of deacetylation (DDA) (\%), molecular weight (kDA), and ash content (\%) were selected as the response (dependent variable) of the study. Optimal design was set to five levels, equivalents to levels $-1,-0.5,0,0.5$, and 1 in order to obtain a lot of information about the main effects in a 
relatively few number of runs besides obtaining more precise of optimum point. All the statistical testing of the model was performed by ANOVA analysis with F-test. The F-values for each model was confirmed significantly with $\mathrm{p}$-value $\leq 0.05$.

\section{Results and discussion}

\subsection{Yield}

The second-order polynomial equation showed a relationship between the independent variables time (h) $\left(\mathrm{X}_{1}\right)$, and temperature of deacetylation $\left({ }^{\circ} \mathrm{C}\right)\left(\mathrm{X}_{2}\right)$ and the dependent variable yield (\%) as:

$$
\begin{aligned}
& \mathrm{Y}=19.36+0.8453 \mathrm{X}_{1}-1.72 \mathrm{X}_{2}-2.21 \mathrm{X}_{1} \mathrm{X}_{2}+ \\
& 1.64 \mathrm{X}_{1}{ }_{1}-5.85 \mathrm{X}_{2}^{2}
\end{aligned}
$$

From the equation (1), the yield (\%) was found to have a quadratic relationship with the two variables. The $\mathrm{R}^{2}$ value (0.9406) (Table 1), being a measure of the goodness of fit of the model. 3D contour plot clearly showed that the yield (\%) of chitosan decreased at $90^{\circ} \mathrm{C}$ as the color gradient changed from red to blue. The yield of chitosan obtained for all the 16 runs ranged from 10.87 to $22.61 \%$. The yield obtained from this study was in ranged with Shanmugam et al. (2012) where chitosan extracted from Donax scortum shells yielded 18.8\% respectively. In this study, yield (\%) of chitosan increased with the increasing time $(\mathrm{h})$ and temperature $\left({ }^{\circ}\right.$ C) of deacetylation but decreased when the time and temperature reached $8 \mathrm{hrs}$ and $90^{\circ} \mathrm{C}$ respectively. The same trend was showed by Patria (2013). The decreased of yield $(\%)$ at $90^{\circ} \mathrm{C}$ and $8 \mathrm{hrs}$ for razor clam shells, probably due to excessive removal of polymers' acetyl group during deacetylation, depolymerization of the chitosan polymer, causing loss of sample mass/weight and chitosan particles loss during washing (Hossain and Iqbal, 2014).

\subsection{Degree of deacetylation}

Based on equation 2, it was found that DDA to have 2FI relationship with the two variables (time and temperature of deacetylation). The following second order polynomial equation showed a relationship between the independent variables time (h) $\left(\mathrm{X}_{1}\right)$, and temperature $\left({ }^{\circ} \mathrm{C}\right)$ of deacetylation $\left(\mathrm{X}_{2}\right)$ and the dependent variable DDA as :
$\mathrm{Y}=48.22+5.30 \mathrm{X}_{1}-5.99 \mathrm{X}_{2}-3.311 \mathrm{X}_{1} \mathrm{X}_{2}$

High F-value and p-value less than 0.05 indicated that the model was significant. $\mathrm{R}^{2}$ value $(0.9301)$ (Table 1) indicated that $93.01 \%$ of the total variation was explained by the model. Contour plot ascertained showed that the DDA\% of chitosan increased when both factors (time and temperature) increased. The DDA of chitosan extracted from razor clam shells from all the 16 runs ranged between 32.34 to $55.76 \%$. The value obtained in this study was in range with the previous study by Majekodunmi et al. (2017) where the DDA of chitosan two samples of bivalve shells, Laevicardium attenuatum and Mytilus edulis were $37.3 \%$ and $69.6 \%$ respectively. The DDA of chitosan varies from $50 \%$ to $99 \%$ (Kalut, 2008).

\subsection{Molecular weight (kDA)}

Equation 3 showed that molecular weight have a linear relationship with time $(\mathrm{h})\left(\mathrm{X}_{1}\right)$ and temperature $\left({ }^{\circ} \mathrm{C}\right)\left(\mathrm{X}_{2}\right)$ of deacetylation as described by the following equation:

$\mathrm{Y}=482.38-79.04 \mathrm{X}_{1}-110.87 \mathrm{X}_{2}$

$\mathrm{R}^{2}$ (Table 1), indicated that $86.16 \%$ of the total variation was explained by the model. Molecular weight decreased as the time (h) and temperature $\left({ }^{\circ} \mathrm{C}\right)$ increased. The molecular weight of chitosan extracted from razor clam obtained from all the 16 runs ranged from 326.571 to $716.285 \mathrm{kDA}$. The molecular weight values obtained in this study was similar to the previous studies by Devikrishna and Remya (2015) and Shanmugam et al. (2012). The present study showed that the molecular weight of chitosan from razor clam decreased as time and temperature of deacetylation increased. The trend was similar to previous study by Patria (2013). Longer duration of alkali treatment and high temperature may result in the higher formation of amine groups, hence the molecular chains of chitosan depolymerized that eventually cause decreases in molecular weight (Patria, 2013).

\subsection{Ash content (\%)}

Equation 4 showed that ash content (\%) to have a linear relationship with time $(\mathrm{h})\left(\mathrm{X}_{1}\right)$ and temperature $\left({ }^{\circ} \mathrm{C}\right)\left(\mathrm{X}_{2}\right)$ of deacetylation as described by the following

Table 1. Model for responses of extracted chitosan with different conditions

\begin{tabular}{ccccccccc}
\hline Response & \multirow{2}{*}{ Source } & $\begin{array}{c}\text { Sequential } \\
\mathrm{p} \text {-value }\end{array}$ & $\begin{array}{c}\text { Lack of Fit } \mathrm{p}- \\
\text { value }\end{array}$ & $\begin{array}{c}\text { Adjusted } \\
\mathrm{R}^{2}\end{array}$ & $\begin{array}{c}\text { Predicted } \\
\mathrm{R}^{2}\end{array}$ & $\mathrm{R}^{2}$ & F-value & p-value \\
\hline Yield & Quadratic & $<0.0001$ & 0.2532 & 0.9109 & 0.8720 & 0.9406 & 31.69 & $<0.0001$ \\
DDA & 2FI & 0.0077 & 0.2391 & 0.9126 & 0.8679 & 0.9301 & 53.19 & $<0.0001$ \\
Mw & Linear & $<0.0001$ & 0.2963 & 0.8403 & 0.7939 & 0.8616 & 40.46 & $<0.0001$ \\
Ash & Linear & $<0.0001$ & 0.4681 & 0.8632 & 0.8258 & 0.8814 & 48.32 & $<0.0001$ \\
\hline
\end{tabular}

Where DDA $=$ degree of deacetylation (\%), $\mathrm{Mw}=$ Molecular weight (kDA). 
equation:

Ash $(\%)=8.08-1.37 \mathrm{X}_{1}-0.094 \mathrm{X}_{2}$

Contour plot showed that the temperature $\left({ }^{\circ} \mathrm{C}\right)$ did not give significant effect to the ash content (\%), while as the time $(\mathrm{h})$ increased, the ash content $(\%)$ decreased. This is because mineral is heat resistant until $800^{\circ} \mathrm{C}$. The residual amount of $\mathrm{CaCO}_{3}$ in the shells left from demineralization step was further removed in the process of deacetylation (Lertsutthiwong et al., 2002). Ash content of chitosan obtained from this study ranged between 6.94 - 9.89\% which was in ranged in between with the previous studies by Ibitoye et al. (2018) and Sarbon et al. (2015) which showed that the ash content of extracted chitin and chitosan from commercial shrimps' shells was $11.77 \%$ and chitosan extracted from mud crab (Scylla olivicea) shells at 5.97\%. The concentration of $\mathrm{HCl}$ used during demineralization step affect the ash contents (Sarbon et al., 2015).

\subsection{Optimization}

The optimum condition for the chitosan extraction are deacetylation time and temperature at $6 \mathrm{~h}$ and $70^{\circ} \mathrm{C}$ respectively with predicted values of yield (\%), DDA $(\%)$, molecular weight ( $\mathrm{kDA})$ and ash content $(\%)$ were $19.36 \%, 48.22 \%, 482.38 \mathrm{kDA}$, and $8.08 \%$ respectively. After validation by t-test, the actual values of yield (\%), degree of deacetylation (\%), molecular weight (kDA) and ash content (\%) at the optimum point were $19.903 \pm 2.367, \quad 50.113 \pm 0.902$, $8.517 \pm 2.094$ respectively.

\section{Conclusion}

The optimum conditions for the extraction of chitosan from razor clam shells were able to be determined. The physicochemical properties of chitosan extracted such as degree of deacetylation (DDA), moisture content and ash content were analyzed as the responding variables to determine the optimum condition for the extractions. The optimum condition for the chitosan extraction is deacetylation time and temperature at $6 \mathrm{~h}$ and $70^{\circ} \mathrm{C}$ respectively with predicted values of yield (\%), DDA (\%), molecular weight (kDA) and ash content (\%) were $19.36 \%, 48.22 \%, 482.38 \mathrm{kDA}$, and $8.08 \%$ respectively.

\section{Acknowledgement}

The authors would gratefully thank Universiti Malaysia Terengganu for the support in completing this research.

\section{References}

Adenan, A.B. (2009). Potential of Razor Clam (Ambal) as Coagulant in Water Treatment Process. Sarawak, Malaysia: Universiti Malaysia Sarawak, PhD. Dissertation.

AOAC. (1990) Official methods of analysis of the Association of Official Analytical Chemistry. 15th ed. USA, Washington, D.C: AOAC.

Devikrishna, S. and Remya, R. (2015). Effect of Degree of Deacetylation and Molecular Weight of Chitosan Extracted from Various Marine Sources on Its Applications. International Journal of Innovative Research in Science, Engineering and Technology, 4 (7), 6078-6083.

Hossain, M.S. and Iqbal, A. (2014). Production and characterization of chitosan from shrimp waste. Journal of the Bangladesh Agricultural University, 12(1), 153-160. https://doi.org/10.3329/ jbau.v12i1.21405

Ibitoye, E.B., Lokman, I.H., Hezmee, M.N.M., Goh, Y.M., Zuki, A.B.Z. and Jimoh, A.A. (2018). Extraction and physicochemical characterization of chitin and chitosan isolated from house cricket. Biomedical Materials, 13, 025009. https:// doi.org/10.1088/1748-605X/aa9dde

Kalut, S.A. (2008). Enhancement of degree of deacetylation of chitin in chitosan production. Universiti Malaysia Pahang, PhD. Dissertation.

Kurniasih, M. and Dewi, R.S. (2018). Toxicity tests, antioxidant activity, and antimicrobial activity of chitosan. IOP Conference Series: Materials Science and Engineering, 349, 012037. https:// doi.org/10.1088/1757-899X/349/1/012037

Lertsutthiwong, P., How, N.C., Chandrkrachang, S. and Stevens, W.F. (2002). Effect of Chemical Treatment on the Characteristics of Shrimp Chitosan. Journal of Metals, Materials and Minerals, 12(1), 11-18.

Majekodunmi, S.O. (2016). Current development of extraction, characterization and evaluation of properties of chitosan and its use in medicine and pharmaceutical industry. American Journal of Polymer Science, 6(3), 86-91.

Majekodunmi, S.O., Olorunsola, E.O. and Uzoaganobi, C.C. (2017). Comparative Physicochemical Characterization of Chitosan from Shells of Two Bivalved Mollusks from Two Different Continents. American Journal of Polymer Science, 7 (1), 15-22.

Mourabet, M., El Rhilassi, A., El Boujaady, H., BennaniZiatni, M. and Taitai, A. (2017). Use of response surface methodology for optimization of fluoride adsorption in an aqueous solution by 
Brushite. Arabian Journal of Chemistry, 10(Suppl.

2), S3292-S3302. https://doi.org/10.1016/

j.arabjc.2013.12.028

Na, C.P.L. (2008). Morphological Assessment and Preliminary Molecular Work on 'Ambal Goyang', Psammobia rostratus (Bivalvia). Sarawak, Malaysia: Universiti Malaysia Sarawak, PhD. Dissertation.

Rabuyan, N.A. and Bakar, W.A.W.A. (2016). Demetallization of toxic and heavy metal in Razor Clam, Ensis Arcuatus utilizing catalytic chelation technique. Malaysian Journal of Catalysis, 1(1), 1216.

Patria, A. (2013). Production and characterization of Chitosan from shrimp shells waste. Aquaculture, Aquarium, Conservation and Legislation, 6(4), 339344.

Sarbon, N.M., Sandanamsamy, S., Kamaruzaman, S.F.S. and Ahmad, F. (2015). Chitosan extracted from mud crab (Scylla olivicea) shells: Physicochemical and Antioxidant Properties. Journal of Food Science and Technology, 52(7), 4266-4275. https:// doi.org/10.1007/s13197-014-1522-4

Shanmugam, A., Subhapradha, N., Suman, S., Ramasamy, P., Saravanan, R., Shanmugam, V. and Srinivasan, A. (2012). Characterization of biopolymer "chitosan" from the shell of donacid clam Donax scortum (Linnaeus, 1758) and its antioxidant activity. International Journal of Pharmacy and Pharmaceutical Science, 4(2), 460465.

Zainal, S., Noorul, F.K., Rihanum, Y.S. and Rahmah, M. (2014). Optimization of Chitosan Extract from Cockle Shell Using Response Surface Methodology (RSM). Asian Journal of Agriculture and Food Science, 2(4), 314-323. 